Article

\title{
Beneficial Effects of Tomato Juice Fermented by Lactobacillus Plantarum and Lactobacillus Casei: Antioxidation, Antimicrobial Effect, and Volatile Profiles
}

\author{
Yiyun Liu ${ }^{\dagger}$, Haiming Chen ${ }^{+} \oplus$, Wenxue Chen, Quipping Zhong, Guanfei Zhang and \\ Weijun Chen * \\ College of Food Science and Technology, Hainan University, Haikou 570228, China; 17889841410@163.com (Y.L.); \\ hmchen168@126.com (H.C.); hnchwx@163.com (W.C.); hainufood88@163.com (Q.Z.), zgfei1021@126.com (G.Z.) \\ * Correspondence: chenwj@hainu.edu.cn; Tel.: 086-898-66256495; Fax: 086-898-66256495 \\ + These authors contributed equally to this work.
}

Received: 3 September 2018; Accepted: 14 September 2018; Published: 16 September 2018

check for updates

\begin{abstract}
Tomato juice was fermented by Lactobacillus plantarum and Lactobacillus casei to produce an innovative high-bioactivity probiotic beverage. The levels of lycopene, total carotenoids, ascorbic acid, total phenolic and volatile compounds, 1,1-diphenyl-2-picrylhydrazyl (DPPH), 2,2'-azinobis-3-ethylbenzotiazo-line-6-sulfonic acid (ABTS) radical scavenging capacities, ferric reducing antioxidant power (FRAP), and Escherichia coli flora, as well as the inhibition of copper-induced human low-density lipoproteins (LDL)-cholesterol oxidation assays, were measured. The results revealed that the ABTS and DPPH inhibition values, as well as the FRAP and total phenolic content, were significantly increased. LDL-cholesterol oxidation was markedly delayed after the addition of the fermented juice. The in vitro inhibitory effects of Escherichia coli flora were substantially increased after being fermented with Lactobacillus plantarum and Lactobacillus casei. The results associated with the volatile compounds indicated that fermentation with Lactobacillus plantarum and Lactobacillus casei is a meaningful strategy for modifying flavors.
\end{abstract}

Keywords: tomato juice; Lactobacillus plantarum; Lactobacillus casei; antioxidant activity; Escherichia coli flora; volatile compounds

\section{Introduction}

Tomato is one of the major vegetables widely consumed worldwide. The health benefits of the tomato are attributed to its abundance in antioxidative components, including lycopene, phenolics, $\beta$-carotene, lutein and ascorbic acid [1-7].

Various studies have demonstrated the benefits of probiotics to human health [8]. Probiotics are routinely utilized in the manufacturing of fermented food products because they enhance the quality, safety, and sensory value of new functional foods [9]. Lactobacillus casei and Lactobacillus plantarum are two major probiotics that significantly enhance the antioxidative and antimicrobial activities of various foods because of their biosurfactants. All analyzed probiotic organisms that produce exopolysaccharides (EPS) under laboratory conditions have strong antibacterial abilities and scavenging activities [10]. Furthermore, fermentation is a well-known strategy for intensifying flavors.

This study aimed to investigate the feasibility of improving the antioxidant activity, antimicrobial ability and flavor of fermented tomato juice by L. plantarum and L. casei. In addition, the content of lycopene, total carotenoids, ascorbic acid, total phenolic and volatile compounds, 1,1-diphenyl-2-picrylhydrazyl (DPPH) and 2,2'-azinobis-3-ethylbenzotiazo-line-6-sulfonic acid (ABTS) 
radical scavenging capacities, ferric reducing antioxidant power (FRAP), and antimicrobial ability (Escherichia coli flora), as well as the inhibition of copper-induced human low-density lipoproteins (LDL)-cholesterol oxidation assays, were measured to determine whether fermentation by L. plantarum and L. casei can improve the bioactivity of tomato juice.

\section{Results and Discussion}

\subsection{Juice Yield, Solid Content and pH Value}

Figure 1 shows the changes in juice yield, solid content, and pH value. Approximately $6656 \mathrm{~g}$ of juice was obtained after processing $7446 \mathrm{~g}$ of tomatoes. The juice yield was $89.4 \%$. The solid content was initially $4.5 \%$ and was adjusted to $12.2 \%$ for fermentation. No significant change was caused by fermentation regardless of bacterial strain (L. casei or L. plantarum) throughout the fermentation; by contrast, the $\mathrm{pH}$ value notably decreased. For L. plantarum, the $\mathrm{pH}$ displayed a downward trend until 3.20 (32 h) and then increased to 3.32 (48 h). For L. casei, the pH sharply dropped to 2.27 ( $24 \mathrm{~h}$ ), increased to $3.43(32 \mathrm{~h})$, and was ultimately stable at 3.11 (48 h). The $\mathrm{pH}$ of the tomato juice fermented by L. casei at $32 \mathrm{~h}$ notably increased. L. casei can survive at such a $\mathrm{pH}$ value. However, $\alpha$-tomatine can be released during the fermentation process, and a greater amount of acid corresponds to a higher $\alpha$-tomatine content. This phenomenon may be the reason why the $\mathrm{pH}$ value increased in both fermented juices after fermentation for a few hours. For L. casei, a previous study has suggested that biogenic amine would be produced [11].
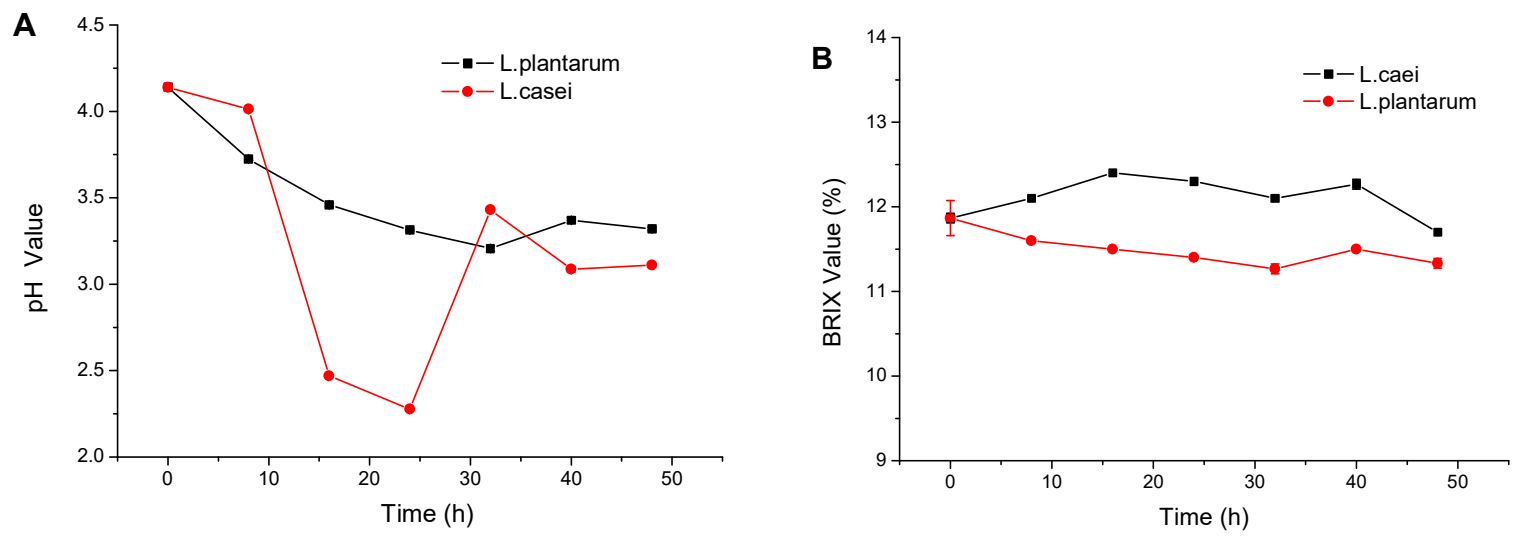

Figure 1. Changes of $\mathrm{pH}(\mathbf{A})$ and Brix values (B) of tomato juice during fermentation.

\subsection{Chemical Characteristics of the Tomato Juice}

Figure 2 illustrates the free radical scavenging activity assay of the tomato juice. The antioxidant activities of L. plantarum and L. casei were evaluated from 0 to $48 \mathrm{~h}$ of fermentation in terms of ABTS assay, DPPH activity, FRAP, and ascorbic acid. The DPPH radical scavenging activity in the tomato juice significantly $(p<0.05)$ grew in the two groups, from $20.48 \%$ to $27.02 \%$ for $L$. casei, and from $20.48 \%$ to $28.57 \%$ for L. plantarum. The same trend was observed in the FRAP assay. Under significance analysis $(p<0.05)$, the data revealed a remarkable increase from 235.67 to $305.02 \mathrm{uM}$ for $L$. casei, and from 235.67 to $280.27 \mathrm{uM}$ for L. plantarum. 

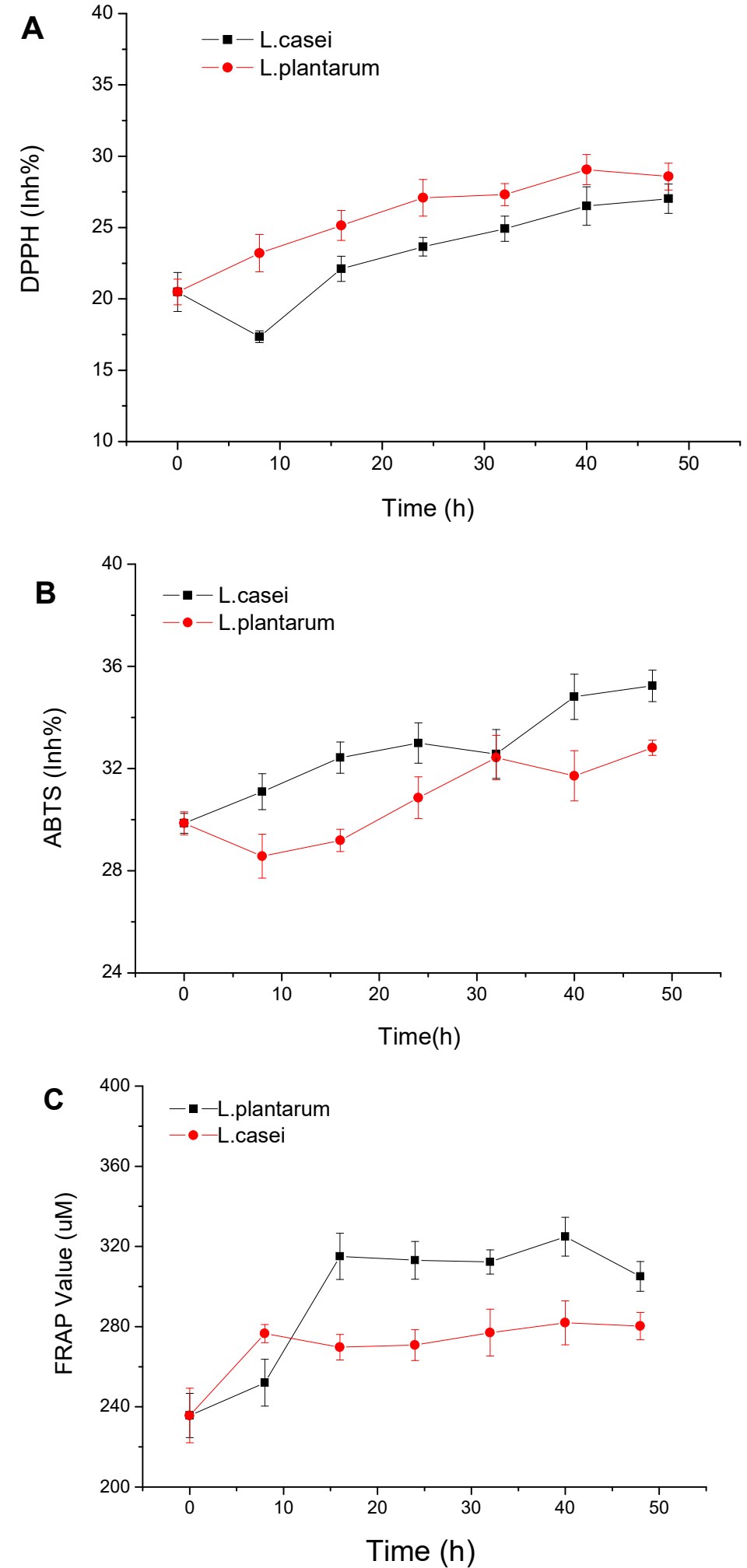

Figure 2. Changes of DPPH (A); ABTS (B) and FRAP (C) values of tomato juice during fermentation.

\subsection{Copper-Induced Human LDL-Cholesterol Oxidation}

LDL-cholesterol (Figure 3) has been found to be unstable, and the addition of antioxidants, such as Trolox, prevents the oxidation of LDL and plasma [12]; our results agree with these findings. As shown in Figure 3, the lag time was $40 \mathrm{~min}$ in the blank group and more than $240 \mathrm{~min}$ in the control (Trolox). Figure 3 shows that the antioxidant capacity of fermented tomato juice (lag time: $80 \mathrm{~min}$ ) 
was higher than that of fresh tomato juice $(60 \mathrm{~min})$ with respect to LDL oxidation. This result was consistent with a previous finding wherein oxidized human LDL-cholesterol induced by copper was inhibited by phenolics [13]. Moreover, the inhibitory effect was correlated with the phenolic content [14]. Numerous studies have indicated that some Lactic acid bacteria (LAB) greatly inhibits the LDL oxidative effects, including those of Lactobacillus (L.) delbrueckii, Bifidobacterium (B.) longum, and Streptococcus thermopillus [15-17]. In addition, tomato juice can increase the resistance of LDL particles from the copper-induced formation of oxidized phospholipids [18], which agreed with our results for L. casei and L. plantarum.

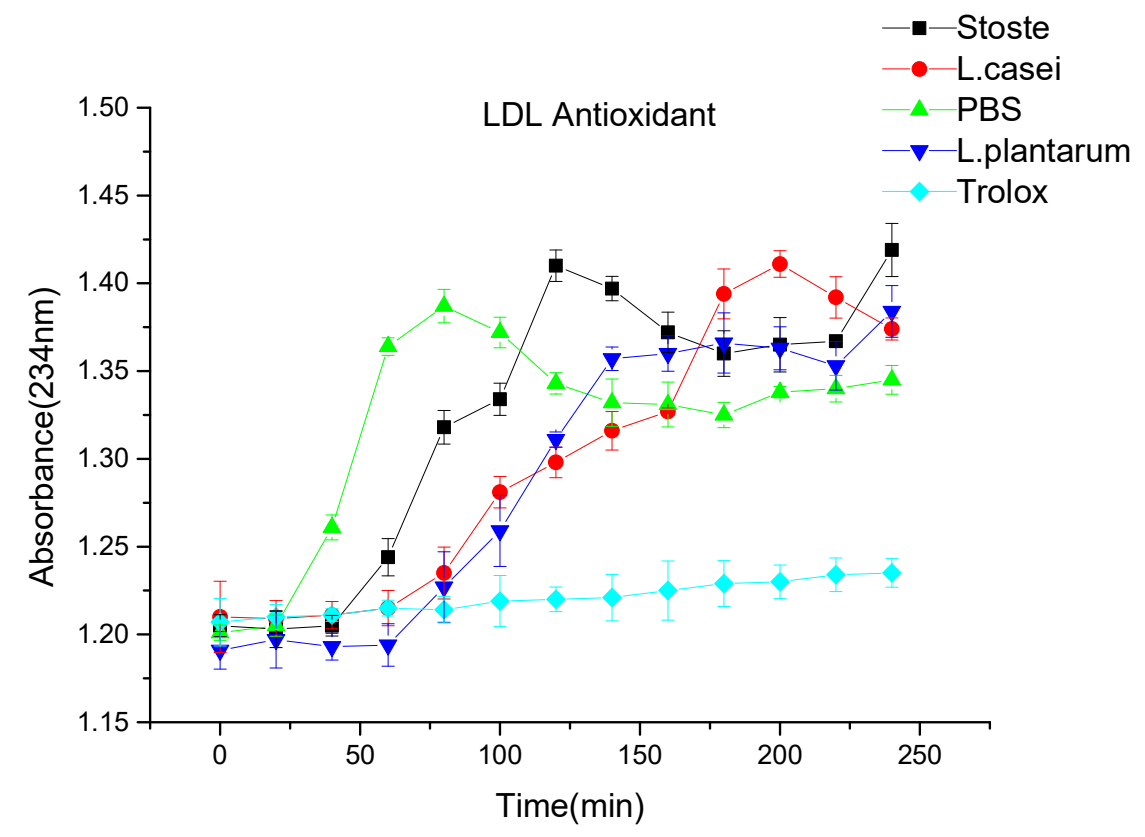

Figure 3. Changes of low-density lipoproteins (LDL)-cholesterol antioxidant capacity of tomato juice during fermentation.

\subsection{Gut Bacteria Inhibition}

As shown in Figure 4, the saline and fresh tomato juice groups ( $10^{-2}$ times diluent) formed quantities of intestinal flora (including E. coli). By contrast, the inhibitory effect of E. coli was displayed well after the fermented juice was poured, regardless of the probiotic used (L. casei or L. plantarum). No marked differences in intestinal flora were observed among the saline, fresh tomato juice, and fermented juice groups. After the fermented juice was poured, the inhibitory effect displayed was possibly due to the following reasons. For the juice fermented by L. casei, LiN333 was found to effectively act against Escherichia. This activity might be due to some unknown characteristics of the outer membrane of L. casei [19]. Moreover, L. plantarum released an effective compound responsible for the important effect of disrupting the E. coli plasma membrane [20]. Other studies have also illustrated that three strains of L. plantarum from Balkan cheeses (CLP1, CLP2, and CLP3) exhibit high antibacterial activities that can be harnessed to control pediatric diarrhea, which is caused by the pathogenic strains of E. coli [21]. In addition, L. plantarum could affect the E. coli-induced passage of mannitol across the intestinal wall [22]. 


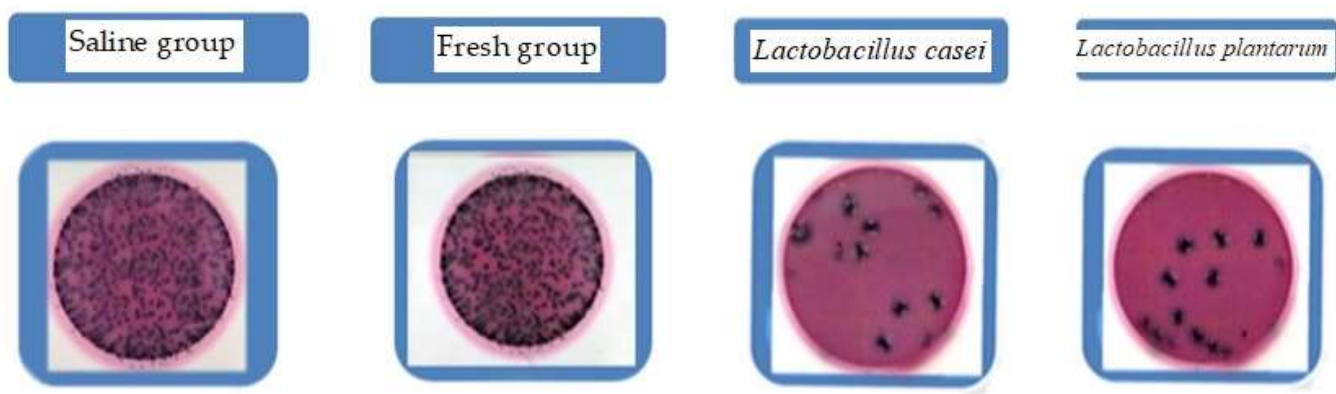

Figure 4. The bactericidal capacity of fresh and fermented tomato juice.

\subsection{Changes of Total Phenolics during Fermentation}

Table 1 shows that the total phenolics in the tomato juice fluctuated slightly but generally increased during fermentation with L. casei. The total phenolics initially peaked at $204.94 \mathrm{ug}$ GAE/mL after 8 $\mathrm{h}$, from $166.05 \mathrm{ug} \mathrm{GAE} / \mathrm{mL}$ initially, followed by a mild downward trend for up to $24 \mathrm{~h}$ (to 153.65 ug GAE/mL), and then by another increase until the end (to $195.55 \mathrm{ug}$ GAE/mL). The L. plantarum group did not change obviously (Table 1), however, it displayed the same trend. The total phenolics initially peaked at $167.42 \mathrm{ug}$ GAE/mL after $8 \mathrm{~h}$, from $166.05 \mathrm{ug}$ GAE/mL initially, followed by a mild downward trend for up to $32 \mathrm{~h}$ (to $152.34 \mathrm{ug} \mathrm{GAE} / \mathrm{mL}$ ), and then by another increase until the end (to $170.04 \mathrm{ug}$ GAE/mL). Phenolic compounds contribute highly to the antioxidative capacity of many plants [23], and this may explain the elevated antioxidative activity in fermented tomato juice. After fermentation by L. casei and L. plantarum [24], the ABTS, DPPH, and FRAP levels markedly increased, and these increases may be due to various reasons. All of the analyzed probiotic organisms produced EPS under laboratory conditions; moreover, probiotic organisms have strong antibacterial ability and strong scavenging activity [10]. For L. plantarum, r-EPS1 and r-EPS2 represent potent antioxidative activities for hydroxyl and DPPH radical scavenging and for reducing power assays [25]. For L. casei, the bio-surfactants from the strains exhibit considerable antioxidant and antiproliferative potencies.

\subsection{Changes in Lycopene, Total Carotenoids, and Ascorbic Acid}

As represented by Table 1, lycopene and total carotenoids levels showed similar tendencies regardless of the bacterial strain used for fermentation (L. casei or L. plantarum). Moreover, lycopene and total carotenoids levels significantly increased after fermentation with L. casei (from 191.51 and $153.55 \mathrm{ug} / \mathrm{mL}$, to 202.41 and $158.56 \mathrm{ug} / \mathrm{mL}$, respectively). By contrast, in Table 1, the tomato juice fermented by L. plantarum fluctuated slightly but generally decreased (from 191.51 and $153.55 \mathrm{ug} / \mathrm{mL}$, to 161.39 and $142.27 \mathrm{ug} / \mathrm{mL}$, respectively). In comparison, the data did not significantly vary for ascorbic acid (for L. casei and L. plantarum).

\subsection{Volatile Compositions of Tomato Juice before and after Fermentation}

Various volatile compounds, including alcohols, hydrocarbons, acids, esters, aldehydes, and ketones, were detected and identified by GC-MS in fresh and fermented (L. casei and L. plantarum) tomato juices, as shown in Table 2. 
Table 1. Changes of tomato juice during fermentation by L. casei $^{\mathrm{c}}$ and L. plantarum ${ }^{1, \mathrm{~d} .}$

\begin{tabular}{|c|c|c|c|c|c|c|c|c|}
\hline Hours of & $\mathrm{TPC}^{2, \mathrm{c}}$ & Lycopene $^{c}$ & $\beta$-Carotinoid ${ }^{c}$ & Ascorbic Acid $^{c}$ & $\mathrm{TPC}^{2, \mathrm{~d}}$ & Lycopene $^{\mathrm{d}}$ & $\begin{array}{c}\text { Total } \\
\text { Carotenoids }\end{array}$ & Ascorbic Acid ${ }^{d}$ \\
\hline & (ug GAE/mL) & (ug/mL) & (ug/mL) & (ug/mL) & (ug GAE/mL) & (ug/mL) & (ug/mL) & (ug/mL) \\
\hline 0 & $166.05 \pm 2.12^{d}$ & $191.51 \pm 2.14^{\mathrm{c}}$ & $153.55 \pm 0.81^{d}$ & $9.77 \pm 2.97^{a, b}$ & $166.05 \pm 9.25^{a}$ & $191.51 \pm 8.75^{a}$ & $153.55 \pm 2.62^{a}$ & $11.65 \pm 1.82^{a}$ \\
\hline 8 & $204.94 \pm 4.75^{\mathrm{a}}$ & $210.34 \pm 3.96^{\mathrm{a}}$ & $161.32 \pm 1.42^{a}$ & $7.94 \pm 0.22^{b}$ & $167.42 \pm 10.97^{a, b}$ & $182.59 \pm 1.91^{\mathrm{a}}$ & $149.67 \pm 0.71^{\mathrm{a}, \mathrm{b}}$ & $12.94 \pm 4.98^{\mathrm{a}}$ \\
\hline 16 & $184.16 \pm 6.47^{b, c}$ & $193.69 \pm 3.96^{c}$ & $154.47 \pm 1.59^{\mathrm{c}, \mathrm{d}}$ & $7.75 \pm 0.77^{b}$ & $165.41 \pm 5.81^{\mathrm{a}, \mathrm{b}}$ & $179.23 \pm 3.57^{\mathrm{a}, \mathrm{b}}$ & $148.24 \pm 1.23^{\mathrm{a}, \mathrm{b}}$ & $11.38 \pm 1.42^{\mathrm{a}}$ \\
\hline 24 & $153.65 \pm 8.19^{d}$ & $200.63 \pm 2.48^{b}$ & $157.03 \pm 0.99^{b, c}$ & $8.56 \pm 0.93^{b}$ & $161.69 \pm 4.61^{b}$ & $188.14 \pm 4.49^{\mathrm{a}, \mathrm{b}}$ & $152.12 \pm 2.18^{a}$ & $12.06 \pm 1.23^{a}$ \\
\hline 32 & $168.07 \pm 7.27^{\mathrm{c}, \mathrm{d}}$ & $202.21 \pm 5.45^{b}$ & $158.46 \pm 2.73^{a, b}$ & $7.86 \pm 0.12^{b}$ & $152.34 \pm 8.37^{b}$ & $192.7 \pm 8.92^{\mathrm{a}, \mathrm{b}}$ & $154.17 \pm 2.73^{a}$ & $14.09 \pm 1.38^{a}$ \\
\hline 40 & $182.82 \pm 10.07^{b, c}$ & $197.46 \pm 2.06^{\mathrm{b}, \mathrm{c}}$ & $156.41 \pm 0.99 b^{c, d}$ & $7.79 \pm 0.12^{b}$ & $169.03 \pm 2.09^{\mathrm{a}, \mathrm{b}}$ & $179.62 \pm 4.22^{\mathrm{a}, \mathrm{b}}$ & $148.64 \pm 1.85^{\mathrm{a}, \mathrm{b}}$ & $13.08 \pm 1.66^{\mathrm{a}}$ \\
\hline 48 & $195.55 \pm 1.59^{\mathrm{a}, \mathrm{b}}$ & $202.41 \pm 3.96^{b}$ & $158.56 \pm 1.87^{\mathrm{a}, \mathrm{b}}$ & $11.11 \pm 1.02^{\mathrm{a}}$ & $170.04 \pm 6.06^{\mathrm{a}, \mathrm{b}}$ & $161.39 \pm 5.95^{b}$ & $142.27 \pm 2.77^{b}$ & $12.13 \pm 0.82^{\mathrm{a}}$ \\
\hline
\end{tabular}

${ }^{1}$ Values are expressed as mean \pm SD; values in the same column followed by different letters (a-d) are statistically different at $p<0.05{ }^{2}$ TPC, total phenolic content. 
Table 2. Major volatile compounds (peak area $\times 10^{6}$ ) and relative peak area (RPA) in fermented tomato juice.

\begin{tabular}{|c|c|c|c|c|c|c|c|}
\hline \multirow[t]{2}{*}{ Category } & \multirow[t]{2}{*}{ Volatile Compounds } & \multicolumn{2}{|c|}{ Tomato Juice } & \multicolumn{2}{|c|}{$\begin{array}{l}\text { Fermented Tomato Juice } \\
\text { (L. casei) }\end{array}$} & \multicolumn{2}{|c|}{$\begin{array}{c}\text { Fermented Tomato Juice } \\
\text { (L. Plantarum) }\end{array}$} \\
\hline & & Peak Area & RPA (\%) & Peak Area & RPA (\%) & Peak Area & RPA (\%) \\
\hline \multirow[t]{33}{*}{ Alcohols } & Ethanol & $45.04 \pm 1$ & 3.83 & $36.8 \pm 0.16$ & 4.33 & $16.95 \pm 0.42$ & 1.61 \\
\hline & 1-Butanol & $2.07 \pm 0.03$ & 0.18 & ND & 0 & ND & 0 \\
\hline & 1-Butanol, 3-methyl- & $58.93 \pm 0.35$ & 5 & $43.8 \pm 0.08$ & 5.15 & $116.16 \pm 0.73$ & 11.04 \\
\hline & 1-Pentanol & $68.14 \pm 1.35$ & 5.79 & $54.16 \pm 0.9$ & 6.37 & $27.58 \pm 0.6$ & 2.62 \\
\hline & 2-Tridecen-1-ol, $(E)$ - & $16.65 \pm 0.75$ & 1.41 & ND & 0 & $\mathrm{ND}^{*}$ & 0 \\
\hline & 1-Penten-3-ol & $15.95 \pm 0.77$ & 1.35 & $4.69 \pm 0.21$ & 0.55 & ND & 0 \\
\hline & (S)-(+)-3-Methyl-1-pentanol & $4.79 \pm 0.1$ & 0.41 & ND & 0 & ND & 0 \\
\hline & 1-Hexanol & $200.44 \pm 0.4$ & 17.02 & $157.42 \pm 6.08$ & 18.51 & $102.69 \pm 0.83$ & 9.76 \\
\hline & 3-Hexen-1-ol, (Z)- & $43.93 \pm 0.97$ & 3.73 & $29.85 \pm 0.28$ & 3.51 & $16.14 \pm 0.08$ & 1.53 \\
\hline & 2-Hepten-1-ol, $(E)-$ & $7.05 \pm 0.1$ & 0.6 & $3.43 \pm 0$ & 0.4 & ND & 0 \\
\hline & 1-Hexanol, 4-methyl-, (S)- & $1.1 \pm 0.04$ & 0.09 & $0.32 \pm 0.01$ & 0.04 & $2.17 \pm 0$ & 0.21 \\
\hline & 1-Octen-3-ol & $9.39 \pm 0.13$ & 0.8 & $4.19 \pm 0.16$ & 0.49 & ND & 0 \\
\hline & 1-Heptanol & $4.6 \pm 0.06$ & 0.39 & $4.44 \pm 0.15$ & 0.52 & $3.01 \pm 0.07$ & 0.29 \\
\hline & 1-Pentanol, 2-methyl- & $0.44 \pm 0.01$ & 0.04 & ND & 0 & ND & 0 \\
\hline & 6-Hepten-1-ol, 2-methyl- & $2.17 \pm 0.1$ & 0.18 & $3.26 \pm 0.14$ & 0.38 & ND & 0 \\
\hline & 2-Propyl-1-pentanol & $1.67 \pm 0.04$ & 0.14 & ND & 0 & ND & 0 \\
\hline & 1-Octanol & $6.82 \pm 0.09$ & 0.58 & $9.93 \pm 0.22$ & 1.17 & $5.4 \pm 0.07$ & 0.51 \\
\hline & Bicyclo[2.2.1]heptan-2-ol, 1,3,3-trimethyl- & $2.35 \pm 0.08$ & 0.2 & ND & 0 & ND & 0 \\
\hline & 5-Isopropenyl-2-methyl-7-oxabicyclo[4.1.0]heptan-2-ol & $0.48 \pm 0.02$ & 0.04 & ND & 0 & ND & 0 \\
\hline & 1-Methylcycloheptanol & $0.65 \pm 0$ & 0.05 & $0.72 \pm 0.04$ & 0.08 & ND & 0 \\
\hline & 2-Octen-1-ol, $(E)-$ & $5.47 \pm 0.11$ & 0.46 & ND & 0 & ND & 0 \\
\hline & Phenylethyl Alcohol & $0.94 \pm 0.05$ & 0.08 & $1.29 \pm 0.02$ & 0.15 & ND & 0 \\
\hline & 2-Hexen-1-ol, (Z)- & $81.11 \pm 2.17$ & 6.89 & $56.7 \pm 0.27$ & 6.67 & $36.09 \pm 1.12$ & 3.43 \\
\hline & .alpha.-Terpineol & ND & 0 & $6.16 \pm 0.02$ & 0.72 & ND & 0 \\
\hline & 3-Nonen-1-ol, (Z)- & ND & 0 & $0.59 \pm 0.01$ & 0.07 & ND & 0 \\
\hline & trans-2-Undecen-1-ol & ND & 0 & $6.92 \pm 0.16$ & 0.81 & ND & 0 \\
\hline & 2-Propyl-1-pentanol & ND & 0 & $6.48 \pm 0.28$ & 0.76 & ND & 0 \\
\hline & 1-Pentanol, 3-methyl- & ND & 0 & $10.19 \pm 0.12$ & 1.2 & $46.72 \pm 1.3$ & 4.44 \\
\hline & 2-Penten-1-ol, (Z)- & ND & 0 & $3.27 \pm 0.08$ & 0.38 & $0.93 \pm 0.05$ & 0.09 \\
\hline & 3-Hexen-1-ol, acetate, $(Z)$ - & ND & 0 & $6.07 \pm 0.13$ & 0.71 & ND & 0 \\
\hline & 2-Penten-1-ol, $(Z)-$ & ND & 0 & $13.74 \pm 0.16$ & 1.62 & ND & 0 \\
\hline & 3-Buten-1-ol, 3-methyl- & ND & 0 & $7.24 \pm 0.31$ & 0.85 & $7.49 \pm 0.36$ & 0.71 \\
\hline & 4-Hexen-1-ol & ND & 0 & $7.09 \pm 0.01$ & 0.83 & ND & 0 \\
\hline
\end{tabular}


Table 2. Cont

\begin{tabular}{|c|c|c|c|c|c|c|c|}
\hline \multirow{2}{*}{ Category } & \multirow{2}{*}{ Volatile Compounds } & \multicolumn{2}{|c|}{ Tomato Juice } & \multicolumn{2}{|c|}{$\begin{array}{c}\text { Fermented Tomato Juice } \\
\text { (L. casei) }\end{array}$} & \multicolumn{2}{|c|}{$\begin{array}{c}\text { Fermented Tomato Juice } \\
\text { (L. Plantarum) }\end{array}$} \\
\hline & & Peak Area & RPA (\%) & Peak Area & RPA (\%) & Peak Area & RPA (\%) \\
\hline & 2-Nonanol & ND & 0 & $4.12 \pm 0$ & 0.49 & ND & 0 \\
\hline & trans-(2-Ethylcyclopentyl)methanol & ND & 0 & $3.21 \pm 0.06$ & 0.38 & ND & 0 \\
\hline & cis-9-Tetradecen-1-ol & ND & 0 & $0.59 \pm 0.02$ & 0.07 & ND & 0 \\
\hline & 2-Furanmethanol & ND & 0 & $1 \pm 0.05$ & 0.12 & ND & 0 \\
\hline & 2-Nonen-1-ol, $(E)$ - & ND & 0 & $0.22 \pm 0.01$ & 0.03 & ND & 0 \\
\hline & Geraniol & ND & 0 & $1.77 \pm 0.06$ & 0.21 & ND & 0 \\
\hline & 5,9-Undecadien-2-ol, 6,10-dimethyl- & ND & 0 & $1.07 \pm 0.03$ & 0.13 & ND & 0 \\
\hline & Bicyclo[3.1.1]hept-2-ene-2-methanol, 6,6-dimethyl- & ND & 0 & $0.42 \pm 0.02$ & 0.05 & ND & 0 \\
\hline & 1,6-Octadien-3-ol, 3,7-dimethyl- & ND & 0 & $18.45 \pm 0.25$ & 2.17 & $14.23 \pm 0.27$ & 1.35 \\
\hline & Acetoin & ND & 0 & ND & 0 & $24.71 \pm 0.64$ & 2.35 \\
\hline & 3-Hexen-1-ol, $(E)$ - & ND & 0 & ND & 0 & $4.15 \pm 0.12$ & 0.39 \\
\hline & 1-Hexanol, 2-ethyl- & ND & 0 & ND & 0 & $41.16 \pm 1.18$ & 3.91 \\
\hline & 3-Furanmethanol & ND & 0 & ND & 0 & $1.12 \pm 0.05$ & 0.11 \\
\hline & Phenylethyl Alcohol & ND & 0 & ND & 0 & $4.51 \pm 0.17$ & 0.43 \\
\hline & 2-Buten-1-ol, 3-methyl- & ND & 0 & ND & 0 & $12.62 \pm 0.29$ & 1.2 \\
\hline & 1-Pentanol, 4-methyl- & ND & 0 & ND & 0 & $9.46 \pm 0.37$ & 0.9 \\
\hline & 3-Hexen-1-ol, acetate, $(E)$ - & ND & 0 & ND & 0 & $2.02 \pm 0.05$ & 0.19 \\
\hline & 6-Hepten-1-ol, 2-methyl- & ND & 0 & ND & 0 & $16.29 \pm 0.01$ & 1.55 \\
\hline & 1-Methylcycloheptanol & ND & 0 & ND & 0 & $1.09 \pm 0.04$ & 0.1 \\
\hline & 2-Tridecen-1-ol, $(E)$ - & ND & 0 & ND & 0 & $3.9 \pm 0.04$ & 0.37 \\
\hline & Citronellol & ND & 0 & ND & 0 & $0.49 \pm 0$ & 0.05 \\
\hline & 3-Nonen-1-ol, (Z)- & ND & 0 & ND & 0 & $0.64 \pm 0.02$ & 0.06 \\
\hline & Geraniol & ND & 0 & ND & 0 & $2.56 \pm 0.02$ & 0.24 \\
\hline & 5,9-Undecadien-2-ol, 6,10-dimethyl- & ND & 0 & ND & 0 & $2.74 \pm 0.11$ & 0.26 \\
\hline & subtotal & 580.18 & 49.26 & 509.64 & 59.92 & 523.04 & 49.7 \\
\hline \multirow{8}{*}{ Hydrocarbons } & Ethylbenzene & $2.2 \pm 0.07$ & 0.19 & ND & 0 & ND & 0 \\
\hline & Benzene, 1,3-dimethyl- & $0.53 \pm 0$ & 0.04 & $0.51 \pm 0.01$ & 0.06 & ND & 0 \\
\hline & p-Xylene & $2.14 \pm 0.05$ & 0.18 & ND & 0 & ND & 0 \\
\hline & 3-Carene & $7.02 \pm 0.17$ & 0.6 & ND & 0 & $5.27 \pm 0.04$ & 0.5 \\
\hline & o-Xylene & $0.87 \pm 0.02$ & 0.07 & $3.4 \pm 0.02$ & 0.4 & ND & 0 \\
\hline & Styrene & $3.88 \pm 0.1$ & 0.33 & $1.15 \pm 0.01$ & 0.13 & ND & 0 \\
\hline & Cyclohexane, ethylidene- & $2.29 \pm 0.02$ & 0.19 & $1.32 \pm 0.01$ & 0.16 & ND & 0 \\
\hline & Propylene Carbonate & $20.37 \pm 0.03$ & 1.73 & ND & 0 & ND & 0 \\
\hline
\end{tabular}


Table 2. Cont.

\begin{tabular}{|c|c|c|c|c|c|c|c|}
\hline \multirow[t]{2}{*}{ Category } & \multirow{2}{*}{ Volatile Compounds } & \multicolumn{2}{|c|}{ Tomato Juice } & \multicolumn{2}{|c|}{$\begin{array}{c}\text { Fermented Tomato Juice } \\
\text { (L. casei) }\end{array}$} & \multicolumn{2}{|c|}{$\begin{array}{c}\text { Fermented Tomato Juice } \\
\text { (L. Plantarum) }\end{array}$} \\
\hline & & Peak Area & RPA (\%) & Peak Area & RPA (\%) & Peak Area & RPA (\%) \\
\hline & Toluene & $2.43 \pm 0.01$ & 0.21 & ND & 0 & ND & 0 \\
\hline & 2-Octene, 2-methyl-6-methylene- & $2.75 \pm 0.02$ & 0.23 & ND & 0 & ND & 0 \\
\hline & 3-Hexen-1-ol, acetate, $(Z)$ - & $1.5 \pm 0.01$ & 0.13 & ND & 0 & ND & 0 \\
\hline & Pentane, 1-nitro- & $24.29 \pm 0.9$ & 2.06 & ND & 0 & ND & 0 \\
\hline & Pentane, 2-nitro- & ND & 0 & $14.43 \pm 0.21$ & 1.7 & ND & 0 \\
\hline & 5-Hepten-2-one, 6-methyl- & $90.79 \pm 3.29$ & 7.71 & $0 \pm 0$ & 0 & ND & 0 \\
\hline & Undecyne & $0.35 \pm 0.01$ & 0.03 & ND & 0 & ND & 0 \\
\hline & Bicyclo[4.1.0]heptane, 7-(1-methylethylidene)- & $1.21 \pm 0.04$ & 0.1 & ND & 0 & ND & 0 \\
\hline & Bicyclo[2.2.1]hept-2-ene, 1,7,7-trimethyl- & ND & 0 & $0.84 \pm 0.02$ & 0.1 & ND & 0 \\
\hline & 1,6-Octadien-3-ol, 3,7-dimethyl- & $5.17 \pm 0.22$ & 0.44 & ND & 0 & ND & 0 \\
\hline & 2-Furanmethanol & $1.67 \pm 0.08$ & 0.14 & ND & 0 & ND & 0 \\
\hline & alpha.-Terpineol & $6.34 \pm 0.24$ & 0.54 & ND & 0 & ND & 0 \\
\hline & Hexadecane, 2,6,10,14-tetramethyl- & $2.39 \pm 0.03$ & 0.2 & $4.7 \pm 0.23$ & 0.55 & $7.08 \pm 0.3$ & 0.67 \\
\hline & 1-Tetradecyne & ND & 0 & $4.95 \pm 0.09$ & 0.58 & ND & 0 \\
\hline & 1-Hexene, 3,3,5-trimethyl- & ND & 0 & $2.52 \pm 0.01$ & 0.3 & ND & 0 \\
\hline & Heneicosane & ND & 0 & $1.37 \pm 0.07$ & 0.16 & ND & 0 \\
\hline & 4-Tridecene, $(Z)$ - & ND & 0 & $0.84 \pm 0.03$ & 0.1 & ND & 0 \\
\hline & D-Limonene & ND & 0 & ND & 0 & $1.87 \pm 0.05$ & 0.18 \\
\hline & Butylated Hydroxytoluene & ND & 0 & ND & 0 & $1.85 \pm 0.04$ & 0.18 \\
\hline & Benzene, 1-methoxy-4-methyl- & ND & 0 & ND & 0 & $0.26 \pm 0.01$ & 0.02 \\
\hline & 1-Hexene, 3,3-dimethyl- & ND & 0 & ND & 0 & $1.99 \pm 0.02$ & 0.19 \\
\hline & Heneicosane & ND & 0 & ND & 0 & $0.82 \pm 0.01$ & 0.08 \\
\hline & 3-Nonen-5-yne, 4-ethyl- & ND & 0 & ND & 0 & $4.09 \pm 0.06$ & 0.39 \\
\hline & 3-Buten-2-one, 4-(2,6,6-trimethyl-1-cyclohexen-1-yl)- & ND & 0 & ND & 0 & $2.4 \pm 0.03$ & 0.23 \\
\hline & subtotal & 178.2 & 15.12 & 36.03 & 4.24 & 25.61 & 2.26 \\
\hline Aldehydes & Hexanal & $175 \pm 0.4$ & 14.86 & ND & 0 & $7.7 \pm 0.03$ & 0.73 \\
\hline & 2-Hexenal, $(E)-$ & $93.72 \pm 3.31$ & 7.96 & ND & 0 & $0.85 \pm 0.02$ & 0.08 \\
\hline & Octanal & $1.4 \pm 0.07$ & 0.12 & ND & 0 & ND & 0 \\
\hline & Nonanal & $8.5 \pm 0.34$ & 0.72 & ND & 0 & $3.55 \pm 0.18$ & 0.34 \\
\hline & Butanal, 3-methyl- & $8.41 \pm 0.12$ & 0.71 & ND & 0 & ND & 0 \\
\hline & 2,4-Hexadienal, $(E, E)$ - & $3.66 \pm 0.06$ & 0.31 & ND & 0 & ND & 0 \\
\hline & Decanal & $0.87 \pm 0.01$ & 0.07 & ND & 0 & $0.28 \pm 0.01$ & 0.03 \\
\hline
\end{tabular}


Table 2. Cont

\begin{tabular}{|c|c|c|c|c|c|c|c|}
\hline \multirow[t]{2}{*}{ Category } & \multirow{2}{*}{ Volatile Compounds } & \multicolumn{2}{|c|}{ Tomato Juice } & \multicolumn{2}{|c|}{$\begin{array}{c}\text { Fermented Tomato Juice } \\
\text { (L. casei) }\end{array}$} & \multicolumn{2}{|c|}{$\begin{array}{l}\text { Fermented Tomato Juice } \\
\text { (L. Plantarum) }\end{array}$} \\
\hline & & Peak Area & RPA (\%) & Peak Area & RPA (\%) & Peak Area & RPA (\%) \\
\hline & 2-Nonenal, $(E)-$ & $1.7 \pm 0.08$ & 0.14 & $0.8 \pm 0.02$ & 0.09 & $0.17 \pm 0$ & 0.02 \\
\hline & Benzene acetaldehyde & $1.05 \pm 0.02$ & 0.09 & ND & 0 & ND & 0 \\
\hline & 2,6-Octadienal, 3,7-dimethyl-, (Z)- & $0.84 \pm 0.01$ & 0.07 & ND & 0 & ND & 0 \\
\hline & 1-Cyclohexene-1-carboxaldehyde, 2,6,6-trimethyl- & $2.45 \pm 0.1$ & 0.21 & ND & 0 & ND & 0 \\
\hline & 2,6-Octadienal, 3,7-dimethyl-, $(E)$ - & $2.78 \pm 0.09$ & 0.24 & ND & 0 & $4.85 \pm 0.09$ & 0.46 \\
\hline & 1H-Pyrrole-2-carboxaldehyde & $0.57 \pm 0.02$ & 0.05 & $0.45 \pm 0.02$ & 0.05 & $0.78 \pm 0.03$ & 0.07 \\
\hline & 2-Undecenal, E- & ND & 0 & $0.58 \pm 0.02$ & 0.07 & ND & 0 \\
\hline & 2-Octenal, $(E)$ - & ND & 0 & ND & 0 & $1.08 \pm 0.05$ & 0.1 \\
\hline & 2,6-Octadienal, 3,7-dimethyl-, (Z)- & ND & 0 & ND & 0 & $0.65 \pm 0.01$ & 0.06 \\
\hline & subtotal. & 300.97 & 25.55 & 1.84 & 0.21 & 19.91 & 1.89 \\
\hline \multirow[t]{20}{*}{ Ketones } & Cyclohexanone, 2,2,6-trimethyl- & $0.56 \pm 0.02$ & 0.05 & ND & 0 & ND & 0 \\
\hline & Acetone & $3.67 \pm 0.07$ & 0.31 & $1.79 \pm 0.05$ & 0.21 & ND & 0 \\
\hline & 4'-(Trifluoromethyl)acetophenone & $0.51 \pm 0.02$ & 0.04 & $3.67 \pm 0.02$ & 0.43 & ND & 0 \\
\hline & trans-beta.-Ionone & $1 \pm 0.02$ & 0.08 & ND & 0 & ND & 0 \\
\hline & $\begin{array}{l}\text { 3-Buten-2-one, } \\
\text { 4-(2,2,6-trimethyl-7-oxabicyclo[4.1.0]hept-1-vl)- }\end{array}$ & $0.38 \pm 0.01$ & 0.03 & $1.46 \pm 0.03$ & 0.17 & $0.47 \pm 0.02$ & 0.04 \\
\hline & 4-Hydroxy-2-methylacetophenone & ND & 0 & $0.25 \pm 0.01$ & 0.03 & $0.61 \pm 0.03$ & 0.06 \\
\hline & 2-Undecanone & ND & 0 & $0.25 \pm 0$ & 0.03 & ND & 0 \\
\hline & 5-Hepten-2-one, 6-methyl- & ND & 0 & $85.9 \pm 3.47$ & 10.1 & $91.68 \pm 3.49$ & 8.71 \\
\hline & 2-Nonanone & ND & 0 & $8.29 \pm 0.4$ & 0.98 & $1.47 \pm 0.06$ & 0.14 \\
\hline & 2-Pentanone & ND & 0 & $23.03 \pm 0.25$ & 2.71 & ND & 0 \\
\hline & 2-Propanone, 1-hydroxy- & ND & 0 & $0.47 \pm 0.02$ & 0.06 & $1.65 \pm 0.08$ & 0.16 \\
\hline & Acetoin & ND & 0 & $0.99 \pm 0.01$ & 0.12 & ND & 0 \\
\hline & 2-Cyclopenten-1-one, 3,4,4-trimethyl- & ND & 0 & ND & 0 & $3.05 \pm 0.06$ & 0.29 \\
\hline & 2-Heptanone & ND & 0 & ND & 0 & $7.75 \pm 0.2$ & 0.91 \\
\hline & 2,3-Butanedione & ND & 0 & ND & 0 & $14.73 \pm 0.24$ & 1.4 \\
\hline & 2-Heptanone & ND & 0 & ND & 0 & $2.62 \pm 0.04$ & 0.25 \\
\hline & 2H-Pyran-2-one, tetrahydro- & ND & 0 & ND & 0 & $0.51 \pm 0$ & 0.05 \\
\hline & 3,5,9-Undecatrien-2-one, 6,10-dimethyl- & ND & 0 & ND & 0 & $0.2 \pm 0$ & 0.02 \\
\hline & $\begin{array}{l}\text { 2(4H)-Benzofuranone, } \\
\text { 5,6,7.7a-tetrahydro-4,4.7a-trimethyl- }(R) \text { - }\end{array}$ & ND & 0 & ND & 0 & $0.37 \pm 0$ & 0.04 \\
\hline & subtotal & 6.12 & 0.51 & 126.1 & 14.84 & 125.09 & 12.07 \\
\hline
\end{tabular}


Table 2. Cont.

\begin{tabular}{|c|c|c|c|c|c|c|c|}
\hline \multirow[t]{2}{*}{ Category } & \multirow[t]{2}{*}{ Volatile Compounds } & \multicolumn{2}{|c|}{ Tomato Juice } & \multicolumn{2}{|c|}{$\begin{array}{c}\text { Fermented Tomato Juice } \\
\text { (L. casei) }\end{array}$} & \multicolumn{2}{|c|}{$\begin{array}{c}\text { Fermented Tomato Juice } \\
(\text { L. Plantarum })\end{array}$} \\
\hline & & Peak Area & RPA (\%) & Peak Area & RPA (\%) & Peak Area & RPA (\%) \\
\hline \multirow[t]{8}{*}{ Acids } & Acetic acid & $32.74 \pm 1.15$ & 2.78 & ND & 0 & $281.29 \pm 3.92$ & 26.72 \\
\hline & Butanoic acid, 3-methyl- & $7.41 \pm 0.31$ & 0.63 & ND & 0 & $22.28 \pm 0.06$ & 2.12 \\
\hline & Butanoic acid, anhydride & ND & 0 & $0.3 \pm 0$ & 0.04 & ND & 0 \\
\hline & Hexanoic acid & $3.84 \pm 0.17$ & 0.33 & $9.17 \pm 0.44$ & 1.08 & $12.85 \pm 0.63$ & 1.22 \\
\hline & Octanoic acid & ND & 0 & $10.6 \pm 0.46$ & 1.25 & $0.36 \pm 0$ & 0.03 \\
\hline & Cyclohexylmethyl formate & ND & 0 & $0.36 \pm 0$ & 0.04 & ND & 0 \\
\hline & Ammonium acetate & ND & 0 & $87.11 \pm 0.25$ & 10.25 & ND & 0 \\
\hline & subtotal. & 43.99 & 3.74 & 107.54 & 12.66 & 316.78 & 30.09 \\
\hline \multirow[t]{8}{*}{ Esters } & Ethyl Acetate & $22 \pm 0.36$ & 1.87 & ND & 0 & ND & 0 \\
\hline & 3-Nonen-5-yne, 4-ethyl- & $4.86 \pm 0.23$ & 0.41 & $5.33 \pm 0.2$ & 0.63 & ND & 0 \\
\hline & Methyl undecyl ether & ND & 0 & $2.86 \pm 0.04$ & 0.34 & ND & 0 \\
\hline & Ethyl tridecanoate & ND & 0 & $3.93 \pm 0.01$ & 0.46 & ND & 0 \\
\hline & Acetic acid, butyl ester & ND & 0 & $4.76 \pm 0.13$ & 0.56 & $3.05 \pm 0.15$ & 0.29 \\
\hline & Dodecanoic acid, methyl ester & ND & 0 & ND & 0 & $0.49 \pm 0$ & 0.05 \\
\hline & Tetradecanoic acid, ethyl ester & ND & 0 & ND & 0 & $0.32 \pm 0.01$ & 0.03 \\
\hline & subtotal & 26.85 & 2.28 & 16.88 & 1.99 & 3.87 & 0.37 \\
\hline \multirow[t]{16}{*}{ Others } & Pyridine & $1.01 \pm 0.05$ & 0.09 & ND & 0 & ND & 0 \\
\hline & 2-Isobutylthiazole & $7.72 \pm 0.35$ & 0.66 & $6.95 \pm 0.13$ & 0.82 & ND & 0 \\
\hline & Oxime-, methoxy-phenyl-_ & $24.13 \pm 1.04$ & 2.05 & $11.44 \pm 0.3$ & 1.35 & ND & 0 \\
\hline & 1H-Isoindole, 3-methoxy-4,7-dimethyl- & $0.63 \pm 0.01$ & 0.05 & ND & 0 & ND & 0 \\
\hline & Benzofuran, 2,3-dihydro- & $1.11 \pm 0.04$ & 0.09 & $1.13 \pm 0.01$ & 0.13 & $17.49 \pm 0.8$ & 1.66 \\
\hline & Phenol, 2,4-bis(1,1-dimethylethyl)- & $2.23 \pm 0.11$ & 0.19 & $1.75 \pm 0.06$ & 0.21 & $2.44 \pm 0.07$ & 0.23 \\
\hline & D-Limonene & ND & 0 & $20.34 \pm 0.69$ & 2.39 & ND & 0 \\
\hline & Butanenitrile, 3-methyl- & ND & 0 & $1.95 \pm 0.01$ & 0.23 & ND & 0 \\
\hline & Oxepine, 2,7-dimethyl- & ND & 0 & $0.87 \pm 0.04$ & 0.1 & ND & 0 \\
\hline & Furfural & ND & 0 & ND & 0 & $6.92 \pm 0.13$ & 0.66 \\
\hline & Ethyl tridecanoate & ND & 0 & ND & 0 & $8.17 \pm 0.02$ & 0.78 \\
\hline & Phenol & ND & 0 & ND & 0 & $0.49 \pm 0.02$ & 0.05 \\
\hline & Methyl tetradecanoate & ND & 0 & ND & 0 & $0.54 \pm 0.02$ & 0.05 \\
\hline & Bicyclo[3.1.1]hept-2-ene-2-methanol, 6,6-dimethyl- & ND & 0 & ND & 0 & $1.26 \pm 0.05$ & 0.12 \\
\hline & 2-Ethylhexyl salicylate & ND & 0 & ND & 0 & $1.31 \pm 0.03$ & 0.12 \\
\hline & subtotal & 36.820377 & 3.13 & 44.435835 & 5.23 & 38.626639 & 3.67 \\
\hline
\end{tabular}

* ND: not detected. 
Table 2 shows that after fermentation with L. casei and L. plantarum, the volatile compounds exhibited kinetic change trends: some increased, some were unchanged, some decreased, and some were similar. Moreover, alcohols, acids, and ketones increased, and hydrocarbons, aldehydes, and esters decreased. Nonetheless, new products were produced differently.

Alcohols were the most abundant group among the volatile compounds in fresh and fermented tomato juices, with total relative peak areas (RPA) of 49.26\% (fresh), 59.92\% (L. casei), and 49.7\% (L. plantarum). Moreover, most alcohols decreased after being fermented by L. plantarum, except for 4-methyl-1-hexanol (from $0.09 \%$ to $0.21 \%$ ). A different situation was observed for the tomato juice fermented by L. casei, in which nearly half increased and the other half decreased. For both strains, quantities of alcohol were produced, resulting in increased total alcohol content.

In addition, Lactobacillus fermentation resulted in increased fatty acid concentration in the fermented tomato juice (Table 2$)$. The newly produced ammonium acetate $(10.25 \%)$ was responsible for this change in the tomato juice fermented by L. casei. Moreover, acetic acid (from 2.78\% to 26.72\%) accounted for this change in the tomato juice fermented by L. plantarum.

Ketones increased from $0.51 \%$ (initially) to $14.84 \%$ (L. casei) and $12.07 \%$ (L. plantarum) after fermentation. Many of the substances came out, especially for 6-methyl-5-hepten-2-one, leading to these notable conversions (10.1\% (L. casei) and $8.71 \%$ (L. plantarum)).

Volatile hydrocarbons, which are another major group of volatile compounds, significantly decreased from $15.12 \%$ (initially) to $4.24 \%$ (L. casei) and 2.26\% (L. plantarum) after fermentation. Moreover, all but 2-, 6-, 10-, and 14-tetramethyl-hexadecane increased in both fermented juices. For the juice fermented by L. casei, 1, 3-dimethyl-benzene increased as well. However, similar to the alcohol group, new products were formed.

The aldehyde categories and levels of fresh and fermented tomato juices are presented in Table 2. After Lactobacillus fermentation, aldehyde concentration significantly decreased from $25.55 \%$ to $0.21 \%$ (L. casei) and $1.89 \%$ (L. plantarum). Apart from the newly produced E-2-Undecenal, the others, after fermentation by L. casei, decreased. By contrast, all concentrations, including those of the newly appeared (E)-2-Octenal and (Z)-3, 7-dimethyl -2,6-Octadienal, decreased after fermentation by $L$. plantarum.

Esters are important components that confer fermented juices with fruity or floral flavors, which form during fermentation. As shown in Table 2, Lactobacillus fermentation slightly reduced the total esters (from $2.28 \%$ (fresh) to $1.99 \%$ (L. casei) and $0.37 \%$ (L. plantarum)) mainly due to the disappearance of ethyl acetate $(1.87 \%$, fresh). However, the newly formed methyl undecyl ether $(0.34 \%)$ and ethyl tridecanoate $(0.46 \%)$ after fermentation by L. casei did not change this situation. After fermentation by L. plantarum, the levels of dodecanoic acid, methyl ester (0.05\%), tetradecanoic acid, and ethyl (0.03\%) ester were not converted.

These changes were probably due to the activity and variety of enzymes related to L. plantarum and chemical changes of L. casei [26]. Alcohols are important in tomato juice flavor. A new class of substances was formed and showed different aromatic components due to various Lactobacillus strains. Esters are aromatic compounds, which appeared as new substances in the fermented tomato juice. Apart from alcohols and esters, other components also appeared in our study, and possibly contributed to the antioxidative and antimicrobial properties of the tomato juice [27].

\section{Materials and Methods}

\subsection{Materials}

Active dry L. plantarum and L. casei were obtained from Lallemand Inc. (Montreal, Quebec, Canada). Tomatoes were bought from the local market. DPPH, ABTS, 6-hydroxy-2,5,7,8-tetramethylchroman2-carboxylic acid (Trolox), and 2,4,6-tris(2-pyridyl)-s-triazine (TPTZ) were acquired from Tokyo Chemical Industry Co., Ltd., (TCI, Tokyo, Japan). Low-density lipoprotein was purchased from ProSpec Inc., (Rehovot, Israel). Folin-Ciocalteu phenol and neocuproine reagents were purchased from Merck 
Corporation (Merck, Darmstadt, Germany). General anaerobic medium and eosin methylene blue were purchased from Hopebio Corporation (Qingdao, China). All other chemicals were of analytical grade unless otherwise stated.

\subsection{Juice Preparation}

Fresh and ripe tomatoes were washed and rid of the ends. The juice was extracted from the tomatoes using a Breville BB1605XL Hemisphere blender (Breville, Sydney, Australia) and a relatively fine tomato juice was obtained by using a plastic filter ( 200 sieve pore). Approximately $500 \mathrm{~mL}$ of the juice was sealed in a plastic bag and refrigerated after pasteurization $\left(90^{\circ} \mathrm{C}, 30 \mathrm{~s}\right)$. The total soluble solid content of the juice was adjusted from $4.6^{\circ}$ Brix to $12.4{ }^{\circ}$ Brix with glucose (final concentration of $5 \%, w / w)$ and then sucrose. Afterward, the fruit juice blends were pasteurized using hot water at 90 ${ }^{\circ} \mathrm{C}$ for $10 \mathrm{~min}$ and cooled under running water. Lastly, we sealed the tomato juice inside sterile plastic bags that were refrigerated at $-80^{\circ} \mathrm{C}$.

\subsection{Microbial Cultivation}

\subsubsection{Open Ampoule}

A degreasing cotton that had been soaked in $75 \%$ alcohol was rubbed along the neck of the ampoule, the top of which was then flame-heated. Sterile water was then dropped to make it break, and tweezers were used to knock down the top.

\subsubsection{Strain Recovery Training}

Aseptic suction drains were used to suction $0.5 \mathrm{~mL}$ MRS and the skim milk liquid medium, which were then dripped into the L. plantarum and L. casei ampoule pipes under gentle shaking. The samples were then fully dissolved in slurry freeze-dried bacteria. All bacterial suspensions were then absorbed by inoculation in MRS and the skim milk medium. The samples were incubated at a constant anaerobic temperature of $37^{\circ} \mathrm{C}$ for $48 \mathrm{~h}$.

\subsubsection{Strain-Activated Cultivation}

The L. plantarum and L. casei were collected from the constant anaerobic temperature incubator and transferred into the MRS and skim milk medium (5\% proportion). The samples were incubated at a constant anaerobic temperature of $37^{\circ} \mathrm{C}$ for $24 \mathrm{~h}$ and then refrigerated at $4{ }^{\circ} \mathrm{C}$.

\subsection{Pretreatment Method}

To determine the water-soluble antioxidant indicator, a pretreatment reagent was prepared at the beginning.

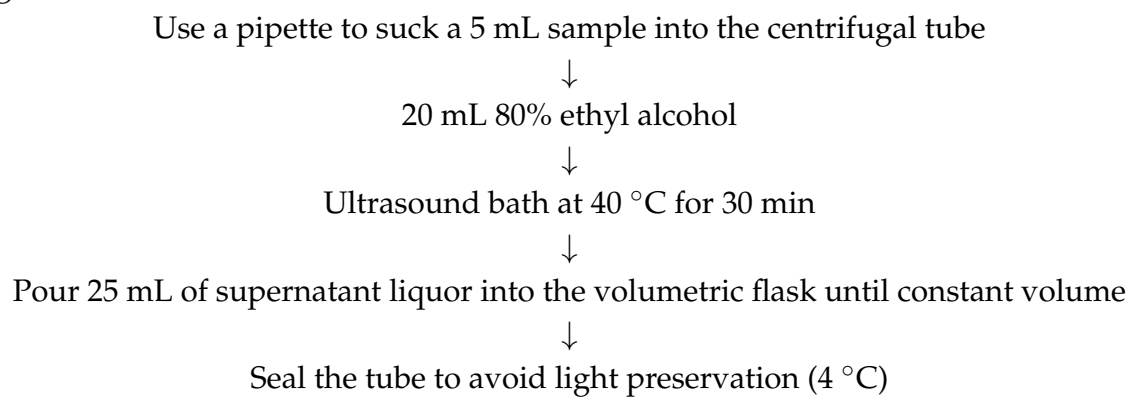




\subsection{Chemical Characteristics of the Fruit Juice Blends}

\subsubsection{Determination of $\mathrm{pH}$ and Total Soluble Solids ( ${ }^{\circ}$ Brix)}

The total soluble solids ( ${ }^{\circ}$ Brix) of the juice were measured using a refractometer (ATAGO, Tokyo, Japan) that had been previously adjusted to zero with distilled water. A pH meter (Hanna Instrument, Poroa de Varzim, Portugal) that had been previously calibrated with buffer solutions (4.86 and 9.18) was used to determine the $\mathrm{pH}$ of the samples.

\subsubsection{Determination of DPPH Radical Scavenging Activity}

A DPPH assay was performed according to a previously described method with slight modifications [28]. The DPPH solution was diluted with ethanol to achieve an absorbance of 1.2-1.3 at $517 \mathrm{~nm}$. For the DPPH assay, $3.5 \mathrm{~mL}$ DPPH solution was added to $0.5 \mathrm{~mL}$ of samples. The solution was mixed well and incubated in the dark at $30{ }^{\circ} \mathrm{C}$ for $45 \mathrm{~min}$. The DPPH absorbance was read at 517 nm by using a TU-1810 spectrophotometer (Persee, Beijing, China). The DPPH radical scavenging capacities of the samples were calculated using the following equation:

$$
\text { DPPH radical scavenging capacity }(\%)=[(\mathrm{A} 0-\mathrm{A} 1) / \mathrm{A} 0] \times 100 \%
$$

where A0 is the absorbance of the control (ethanol) and A1 is the absorbance of the sample.

\subsubsection{Determination of ABTS. Radical Scavenging Activity}

The ABTS radical scavenging activity of the tomato juice was measured using a previously described procedure [29]. ABTS stock solution (2 mL of ABTS stock solution (0.01 M) added to 58 $\mathrm{mL}$ phosphate buffer saline, $\mathrm{pH}$ 6.9) was incubated for $12 \mathrm{~h}$ and diluted with ethanol to achieve an absorbance of $0.70( \pm 0.02)$ at $734 \mathrm{~nm}$ and equilibrated at $30^{\circ} \mathrm{C}$, and the absorbance was read at $734 \mathrm{~nm}$.

The ABTS radical scavenging capacities of the samples were calculated using the following equation:

$$
\text { ABTS radical scavenging capacity }(\%)=[(\mathrm{A} 0-\mathrm{A} 1) / \mathrm{A} 0] \times 100 \%
$$

where $\mathrm{A} 0$ is the absorbance of the control (ethanol) and A1 is the absorbance of the sample.

\subsubsection{FRAP Assay}

A FRAP assay was performed according to a previously described method [30]. The FRAP reagent, which consisted of acetate buffer solution $(0.3 \mathrm{M}, \mathrm{pH} 3.6), \mathrm{FeCl}_{3} \cdot 6 \mathrm{H}_{2} \mathrm{O}$ solution $(20 \mathrm{mM})$, and TPTZ solution $(10 \mathrm{mM}$ in $40 \mathrm{mM} \mathrm{HCl})(10: 1: 1, \mathrm{v} / \mathrm{v} / \mathrm{v})$, was added to $0.5 \mathrm{~mL}$ of extraction solution and kept in the dark for $30 \mathrm{~min}$. The absorbance of the mixture was detected at $593 \mathrm{~nm}$ by using a TU-1810 spectrophotometer (Persee, Beijing, China). $\mathrm{FeSO}_{4} \cdot 7 \mathrm{H}_{2} \mathrm{O}$ was used as the standard, and the results were expressed as $\mu \mathrm{M} \mathrm{FeSO} \cdot 7 \mathrm{H}_{2} \mathrm{O}$ equivalents.

\subsubsection{Determination of Total Phenolic Compounds (TPC)}

The total phenolic compounds in the tomato juice were determined using the Folin-Ciocalteu reagent, with gallic acid as the standard according to a previously described method with slight modifications [31]. The sample $(0.5 \mathrm{~mL})$ was diluted with deionized water $(3.3 \mathrm{~mL})$ and added with Folin-Ciocalteu reagent $(0.2 \mathrm{~mL})$. The sample was placed in the dark at room temperature for $5 \mathrm{~min}$. Afterward, $10 \% \mathrm{Na}_{2} \mathrm{CO}_{3}$ was transfused with $1.3 \mathrm{~mL}$ saturated solution, and then the mixture was left in the dark for $1.5 \mathrm{~h}$. The absorbance of the mixture was evaluated by contrasting with a blank reagent at $765 \mathrm{~nm}$ by using a TU-1810 spectrophotometer (Persee, Beijing, China). Gallic acid (0-8.2 $\mu \mathrm{g} / \mathrm{m})$ was used as the standard comparison. The total phenolic compounds were expressed as gallic acid equivalents per milliliter of sample. 


\subsubsection{Determination of Lycopene and Total Carotenoids}

The lycopene and total carotenoids contents were determined using spectrophotometry according to the method of Bamidele and Fasogbon [23]. A mixture of hexane-acetonitrile-ethanol [50:25:25 $(v / v / v)]$ was used to extract the lycopene and total carotene. In briefly, an approximately 1-mL sample was extracted from the $50-\mathrm{mL}$ solvent mixture. The mixture was placed in the dark to extract the carotenoids with stirring (15 min) on a magnetic stirring plate. Distilled water $(3 \mathrm{~mL})$ was added to the mixture, stirred for another $5 \mathrm{~min}$. Then the mixture was allowed to settle until the phase separation ( $\sim 5 \mathrm{~min}$ ). The contents of lycopene and total carotenoids were obtained by measuring the absorbance of the filtered hydrophobic phase at 503 and $450 \mathrm{~nm}$, respectively. Hexane was used as the blank.

\subsubsection{Ascorbic Acid Content (AA)}

The AOAC (2005) method was used to determine the ascorbic acid content [32]. A pipette was used to transfuse $20 \mathrm{~mL}$ of tomato juice to produce up to $50 \mathrm{~mL}$ with oxalic acid $(0.1 \mathrm{M})$ and then filtered. The filtrate $(5 \mathrm{~mL})$ was dispensed into a beaker with a pipette and titrated with standardized 2, 6-dichlorophenol indophenol dye. The colored solution changed from orange to pink to mark the endpoint of the titration. The procedure was repeated 3 times. Ascorbic acid was used as the standard comparison.

\subsubsection{Copper-Induced Human LDL-Cholesterol Oxidation}

The in vitro LDL-cholesterol oxidation procedure used was conducted according to a previously described method [33] with slight modifications. The LDL was diluted with PBS (10 mM, pH 7.4) to a concentration of $100 \mu \mathrm{g} / \mathrm{mL}$, and oxidation was initiated by $\mathrm{Cu}^{2+}$ (final concentration: $5 \mu \mathrm{M}$ ). The oxidation kinetics were measured based on the change in absorbance at $234 \mathrm{~nm}$ by using a TU-1810 spectrophotometer (Persee, Beijing, China), in which the absorbance was monitored every $20 \mathrm{~min}$ at $37^{\circ} \mathrm{C}$ for $4 \mathrm{~h}$. The absorbance-time curve can be divided into three states: lag, propagation, and decomposition phases. The interception point of the tangents of the lag and propagation phases was defined as the lag time. We chose a slope that demonstrated antioxidant activity (a higher slope corresponded to a worse antioxidant activity). For the assay, LDL (4 mL) was added to fermented tomato juice (final concentration of $0.05 \mathrm{~mL} / \mathrm{mL}$ ), tomato juice (final concentration of $0.05 \mathrm{~mL} / \mathrm{mL}$ ), and Trolox solution (final concentration of $0.005 \mathrm{mg} / \mathrm{mL}$ ) and incubated at $37^{\circ} \mathrm{C}$ for $15 \mathrm{~min}$. Afterward, peroxidation was initiated with $5 \mu \mathrm{MCuSO}_{4}$ solution.

\subsubsection{Effects of Fermented Fruit and Vegetable on the Intestinal Flora}

All groups used the same saline dilute stool suspension (1:10) that was pipetted (1 mL) to the initial test tube. Afterward, concentration gradient dilution was performed to determine the appropriate concentration of the saline dilute stool suspension ( $\mathrm{pH}$ value was adjusted at 6.5-7.5). Then, $1 \mathrm{~mL}$ diluted liquid was transferred from the test tube with an appropriate concentration to $3 \mathrm{M}^{\mathrm{TM}}$ Petrifilm ${ }^{\mathrm{TM}}$ E. coli/Coliform Count (EC) Plates (Minnesota Mining Manufacturing (Shanghai) International Trade Co., Ltd) [34]. As shown in Figure 4, the red dot with the bubble is the intestinal flora, and the blue one is E. coli.

\subsubsection{Determination of Volatile Compounds}

The volatile compounds were analyzed using headspace-solid phase microextraction sampling combined with gas chromatography-mass spectrometry (GC-MS) according to a previously described method [9]. Approximately $50 \%$ of the sample volume was added with $0.30 \mathrm{~g} / \mathrm{mL} \mathrm{NaCl}$ in a headspace glass. Carboxen/Polydimethylsiloxane (CAR/PDMS) $(75 \mu \mathrm{m})$ (Sigma-Aldrich, Saint Louis, MO, USA) fiber was used for extraction for $40 \mathrm{~min}$ at $50{ }^{\circ} \mathrm{C}$, followed by desorption for $3 \mathrm{~min}$ at $230{ }^{\circ} \mathrm{C}$. The data were collected using GC solution software (Shimadzu, Kyoto, Japan). Identification was achieved by 
matching the mass spectrum against the National Institute of Standards and Technology (NIST) 11 libraries and confirmed with the linear retention index values.

\section{Conclusions}

This study demonstrated that tomato juice can be fermented with selected LAB (L. casei and $L$. plantarum) as probiotic microorganisms in order to improve its antioxidative effects, regardless of the anti-E. coli and aroma effects. Therefore, fermenting with L. casei and L. plantarum can make tomato juice a potential probiotic product that is highly functional and health enhancing.

Author Contributions: Conceptualization, H.C. and W.C (Weijun Chen); Methodology, W.C. (Wenxue Chen); Software, Q.Z.; Validation, H.C. and Q.Z.; Formal Analysis, G.Z.; Investigation, W.C. (Wenxue Chen) Resources, W.C. (Weijun Chen); Data Curation, Y.L.; Writing-Original Draft Preparation, Y.L.; Writing-Review \& Editing, H.C.

Funding: This research was funded by [National Natural Science Foundation of China] grant number [31801494], [Natural Science Foundation of Hainan Province of China] grant number [317002] and [Hainan University Start-up Scientific Research Projects of China grant number [kyqd1551; kyqd1630].

Acknowledgments: We would like to thank Prof. Hong-Li Luo, Hainan Key Laboratory for Sustainable Utilization of Tropical Bioresource, for the much-valued help and design suggestions.

Conflicts of Interest: The authors declare no conflict of interest.

\section{References}

1. Nazir, N.; Adrian, M.R. The improvement lycopene availability and antioxidant activities of tomato (Lycopersicum Esculentum, Mill) Jelly Drink. Agric. Agric. Sci. Proc. 2016, 9, 328-334. [CrossRef]

2. Durante, M.; Montefusco, A.; Marrese, P.P.; Soccio, M.; Pastore, D.; Piro, G.; Lenucci, M.S. Seeds of pomegranate, tomato and grapes: An underestimated source of natural bioactive molecules and antioxidants from agri-food by-products. J. Food Compos. Anal. 2017, 63, 65-72. [CrossRef]

3. Bergougnoux, V. The history of tomato: From domestication to biopharming. Biotechnol. Adv. 2014, 32, 170-189. [CrossRef] [PubMed]

4. Kips, L.; De Paepe, D.; Van Meulebroek, L.; Van Poucke, C.; Larbat, R.; Bernaert, N.; Van Pamel, E.; De Loose, M.; Raes, K.; Van Droogenbroeck, B. A novel spiral-filter press for tomato processing: Process impact on phenolic compounds, carotenoids and ascorbic acid content. J. Food Eng. 2017, 213, 27-37. [CrossRef]

5. Montesano, D.; Fallarino, F.; Cossignani, L.; Bosi, A.; Simonetti, M.S.; Puccetti, P.; Damiani, P. Innovative extraction procedure for obtaining high pure lycopene from tomato. Eur. Food Res. Technol. 2008, 226, 327-335. [CrossRef]

6. Fattore, M.; Montesano, D.; Pagano, E.; Teta, R.; Borrelli, F.; Mangoni, A.; Albrizio, S. Carotenoid and flavonoid profile and antioxidant activity in "Pomodorino Vesuviano" tomatoes. J. Food Compos. Anal. 2016, 53, 61-68. [CrossRef]

7. Montesano, D.; Gennari, O.; Seccia, S.; Albrizio, S. A Simple and Selective Analytical Procedure for the Extraction and Quantification of Lutein from Tomato By-Products by HPLC-DAD. Food Anal. Method. 2012, 5, 710-715. [CrossRef]

8. Chua, K.J.; Kwok, W.C.; Aggarwal, N.; Sun, T.; Chang, M.W. Designer probiotics for the prevention and treatment of human diseases. Curr. Opin. Chem. Biol. 2017, 40, 8-16. [CrossRef] [PubMed]

9. Zhang, J.; Luo, M.; Wang, X.; Xiaohui, H.U.; Zhao, J.; Cui, L.; Amp, N.A.; University, F. Optimization of SPME-GC/MS to Determine Tomato Flavoring Components. North. Hortic. Chn. 2017, 13, 7-13. [CrossRef]

10. Li, S.; Huang, R.; Shah, N.P.; Tao, X.; Xiong, Y.; Wei, H. Antioxidant and antibacterial activities of exopolysaccharides from Bifidobacterium bifidum WBIN03 and Lactobacillus plantarum R315. J. Dairy Sci. 2014, 97, 7334-7343. [CrossRef] [PubMed]

11. Nishino, N.; Hattori, H.; Wada, H.; Touno, E. Biogenic amine production in grass, maize and total mixed ration silages inoculated with Lactobacillus casei or Lactobacillus buchneri. J. Appl. Microbio. 2007, 103, 325-332. [CrossRef] [PubMed]

12. Kleinveld, H.A.; Hak-Lemmers, H.L.; Stalenhoef, A.F.; Demacker, P.N. Improved measurement of low-density-lipoprotein susceptibility to copper-induced oxidation: application of a short procedure for isolating low-density lipoprotein. Clin. Chem. 1992, 38, 2066-2072. [PubMed] 
13. de Camargo, A.C.; Regitanod'Arce, M.A.; Biasoto, A.C.; Shahidi, F. Low molecular weight phenolics of grape juice and winemaking byproducts: antioxidant activities and inhibition of oxidation of human low-density lipoprotein cholesterol and DNA strand breakage. J. Agr. Food Chem. 2014, 62, 12159-12171. [CrossRef] [PubMed]

14. Khan, N.; Monagas, M.; Andres-Lacueva, C.; Casas, R.; Urpí-Sardà, M.; Lamuela-Raventós, R.M.; Estruch, R. Regular consumption of cocoa powder with milk increases HDL cholesterol and reduces oxidized LDL levels in subjects at high-risk of cardiovascular disease. Nutr. Metab. Cardiov. Dis. 2012, 22, 1046-1053. [CrossRef] [PubMed]

15. Terahara, M.; Kurama, S.; Takemoto, N. Prevention by lactic acid bacteria of the oxidation of human LDL. Biosci. Biotech. Bioch. 2001, 65, 1864-1868. [CrossRef]

16. Lee, D.K.; Jang, S.; Baek, E.H.; Mi, J.K.; Lee, K.S.; Shin, H.S.; Chung, M.J.; Jin, E.K.; Kang, O.L.; Ha, N.J. Lactic acid bacteria affect serum cholesterol levels, harmful fecal enzyme activity, and fecal water content. Lipids Health Dis. 2009, 8, 21. [CrossRef] [PubMed]

17. Astuti, A.; Umniyati, S.; Rakhmawati, A.; Yulianti, E. Utilization probiotic lactic acid bacteria fish from waste faeces on LDL level blood broiler chickens strain lohmann. Jurnal Sains Dasar 2016, 5, 48-51. [CrossRef]

18. Silaste, M.L.; Alfthan, G.; Aro, A.; Kesäniemi, Y.A.; Hörkkö, S. Tomato juice decreases LDL cholesterol levels and increases LDL resistance to oxidation. Brit. J. Nutr. 2007, 98, 1251-1258. [CrossRef] [PubMed]

19. Ullah, N.; Wang, X.; Wu, J.; Guo, Y.; Ge, H.; Li, T.; Khan, S.; Li, Z.; Feng, X. Purification and primary characterization of a novel bacteriocin, LiN333, from Lactobacillus casei, an isolate from a Chinese fermented food. Food Sci. Technol. 2017, 84, 867-875. [CrossRef]

20. Puertollano, E.; Puertollano, M.A.; Cruz-Chamorro, L.; De Cienfuegos, G.Á.; Ruiz-Bravo, A.; De Pablo, M.A. Effects of concentrated supernatants recovered from Lactobacillus plantarum on Escherichia coli growth and on the viability of a human promyelocytic cell line. J. Appl. Microbiol. 2010, 106, 1194-1203. [CrossRef] [PubMed]

21. Chingwaru, W.; Vidmar, J. Potential of Zimbabwean commercial probiotic products and strains of Lactobacillus plantarum as prophylaxis and therapy against diarrhoea caused by Escherichia coli in children. Asian Pac. J. trop. Med. 2017, 10, 57-63. [CrossRef] [PubMed]

22. Mangell, P.; Nejdfors, P.; Wang, M.; Ahrné, S.; Weström, B.; Thorlacius, H.; Jeppsson, B. Lactobacillus plantarum 299v inhibits escherichia coli-induced intestinal permeability. Digest. Dis. Sci. 2002, 47, 511-516. [CrossRef] [PubMed]

23. Bamidele, O.P.; Fasogbon, M.B. Chemical and antioxidant properties of snake tomato (Trichosanthes cucumerina) juice and Pineapple (Ananas comosus) juice blends and their changes during storage. Food Chem. 2017, 220, 184-189. [CrossRef] [PubMed]

24. Gao, D.; Gao, Z.; Zhu, G. Antioxidant effects of lactobacillus plantarum via activation of transcription factor nrf2. Food Funct. 2013, 4, 982-989. [CrossRef] [PubMed]

25. Wang, K.; Li, W.; Rui, X.; Chen, X.; Jiang, M.; Dong, M. Structural characterization and bioactivity of released exopolysaccharides from Lactobacillus plantarum 70810. Int. J. Biol. Macromol. 2014, 67, 71-78. [CrossRef] [PubMed]

26. Sumby, K.M.; Grbin, P.R.; Jiranek, V. Microbial modulation of aromatic esters in wine: Current knowledge and future prospects. Food Chem. 2010, 121, 1-16. [CrossRef]

27. Cagno, R.D.; Surico, R.F.; Paradiso, A.; Angelis, M.D.; Salmon, J.C.; Buchin, S.; Gara, L.D.; Gobbetti, M. Effect of autochthonous lactic acid bacteria starters on health-promoting and sensory properties of tomato juices. Int. J. Food Microbiol. 2009, 128, 473-483. [CrossRef] [PubMed]

28. Brandwilliams, W.; Cuvelier, M.E.; Berset, C. Use of a free radical method to evaluate antioxidant activity. LWT - Food Sci. Technol. 1995, 28, 25-30. [CrossRef]

29. Re, R.; Pellegrini, N.; Proteggente, A.; Pannala, A.; Yang, M.; Riceevans, C. Antioxidant activity applying an improved ABTS radical cation decolorization assay. Free Radic. Biol. Med. 1999, 26, 1231-1237. [CrossRef]

30. Benzie, I.F.; Strain, J.J. The ferric reducing ability of plasma (FRAP) as a measure of "antioxidant power": the frap assay. Anal. Biochem. 1996, 239, 70-76. [CrossRef] [PubMed]

31. Zheng, W.; Wang, S.Y. Antioxidant activity and phenolic compounds in selected herbs. J. Agr. Food Chem. 2001, 49, 5165-5170. [CrossRef]

32. AOAC (2005): Official Methods of Analysis. 18th ed. Association of Official Analytical Chemists, Gaithersburg, USA. 
33. Abuamsha, R.; Croft, K.D.; Puddey, I.B.; Proudfoot, J.M.; Beilin, L.J. Phenolic content of various beverages determines the extent of inhibition of human serum and low-density lipoprotein oxidation in vitro: Identification and mechanism of action of some cinnamic acid derivatives from red wine. Clin. Sci. 1996, 91, 449-458. [CrossRef]

34. Manohar, G.K.; Khan, S.; Jashbhai, P.B. Comparison of $3 \mathrm{M}^{\mathrm{TM}}$ Petrifilm ${ }^{\mathrm{TM}}$ E. coli/Coliform Count (EC) Plates vs. Is methods for enumeration of Coliforms (IS-5401 Part-1) and E. coli (IS 5887: Part-1) to evaluate quality of Indian milk and milk products. Indian J. Dairy Sci. 2017, 70, 193-199.

Sample Availability: Samples of the compounds are not available from the authors.

(C) 2018 by the authors. Licensee MDPI, Basel, Switzerland. This article is an open access article distributed under the terms and conditions of the Creative Commons Attribution (CC BY) license (http:/ / creativecommons.org/licenses/by/4.0/). 